\title{
APPROACHES TO HANDLING, BREEDING, STRAIN PRESERVATION, GENOTYPING, AND DRUG ADMINISTRATION FOR MOUSE MODELS OF CANCER
}

\author{
Dawnalyn Boggess, Kathleen A. Silva, Carlisle P. Landel, Larry Mobraaten, \\ AND JoHn P. SUNDBERG \\ The Jackson Laboratory, Bar Harbor, Maine
}

\begin{abstract}
Mouse models are extremely valuable biomedical tools for cancer research. Their value to individual investigators depends upon the investigator's ability to manage a colony and manipulate the mice. Basic genotyping to maintain a colony of genetically engineered mice is a critical technique. Understanding the differences between inbred and outbred (nonsegregating vs. segregating backgrounds) determines the reproducibility of models. Preserving valuable colonies for future use through cryopreservation of embryos, sperm, or just the constructs used to create the models enables future work to be done. This chapter provides a broad overview of many of the methods commonly used to perform these tasks as well as how and where to find more specific information.
\end{abstract}

\section{INTRODUCTION}

Inbred laboratory mice have long been the species of choice for biomedical research because (1) of the relatively low cost for maintaining a colony; (2) with inbreeding, mice become genetically identical to each other; (3) numerous reagents are available for very specialized testing; (4) there is a high degree of genetic homology between mice and humans; and (5) there are many sophisticated genetic tools available for working with mice. Mutations in laboratory mice do occur spontaneously. This may be due to inbreeding, where two alleles of a deleterious recessive allele become manifest.
Alternatively, insertional mutagenesis may occur when a retrovirus integrates within the mouse genome. Genetic engineering has become technically accessible to many laboratories where overexpression (transgenesis), underor nonexpression (targeted mutagenesis or the so-called knockout approaches), or selective temporal expression (so-called gene switch methods) of specific, known genes can now be done. Random point mutagenesis has come back into vogue using ethylnitrosourea (ENU) or ethylmethanesulfonate (EMS). All of these approaches provide an array of potential or real models for the study of many types of diseases, including cancer (Nakamura et al., 2002a, b).

Maintaining and working with all of these types of mice are challenging, even for those scientists familiar with conventional inbred strains. Detailed texts are available on systematic workup and characterization methods for mutant mice (Sundberg and Boggess, 2000), general background diseases, including cancer, in commonly used strains (Maronpot et al., 1999; Mikaelian et al., 2004; Mohr et al., 1996), or details on specific organ systems (Smith et al., 2002; Sundberg, 1994b; Ward et al., 2000) which are beyond the scope of this book. Much of this information, including color images, is coming on-line through sources such as the Mouse Tumor Biology Database (http://tumor.informatics.jax.org/FMPro?-db $=$ TumorInstance $\&$-format $=$ mtdp.html\&-view), MousePhenomeDatabase (http://aretha.jax.org/pubcgi/phenome/ mpdcgi?rtn=docs/home), and European Mouse Pathology

Mouse Models of Human Cancer, edited by Eric C. Holland ISBN 0-471-44460-X Copyright (c) 2004 John Wiley \& Sons, Inc. 
Table 1.1. Information on distributors of mice, databases on genetics, genomics, and pathology

Distributors of mutant mice and mouse production services

B\&K Universal, LTD.

Charles River, Inc.

MRC ENU-Mouse Mutagenesis Programme

The ENU-Mouse Mutagenesis Screen Project

The European Mutant Mouse Archive

Harlan Sprague Dawley, Inc.

Harwell Mouse Stock List

Incyte Genomics, Mouse Knockout Services

International Mouse Strains Resource

JAX Mice

Lexicon Genetics, Inc.

National Institute of Genetics (Japan)

Taconic, Inc.

University of Michigan Transgenic Animal Model Core

Database of Gene Knockouts

Induced Mutant Resource (IMR),

Mouse Knockout \& Mutation Database

Mutant Mouse Regional Resource Centers (MMRRC)

Transgenic and Targeted Mutation Database (TBASE)

Transgenic List

U.C.D. Genetically Engineered Mouse Research http://www.bku.com/

http://www.criver.com/

http://www.mgu.har.mrc.ac.uk/mutabase/

http://www.gsf.de/isg/groups/enu-mouse.html

http://www.emmanet.org

http://www.harlan.com/

http://www.mgu.har.mrc.ac.uk/stocklist/stocklist.html

http://www.incyte.com/reagents/knockouts/index.shtml

http://www.jax.org/pub-cgi/imsrlist

http://jaxmice.jax.org/index.shtml

http://www.lexgen.com/

http://www.shigen.nig.ac.jp/mouse/mouse.default.html

http://www.taconic.com/

http://www.med.umich.edu/tamc/

http://www.bioscience.org/knockout/knochome.htm

http://www.jax.org/resources/documents/imr/

http://research.bmn.com/mkmd

http://www.mmrrc.org/

http://tbase.jax.org/

http://www.med.ic.ac.uk/db/dbbm/tglist.htm

http://ccm.ucdavis.edu/tgmouse/

Cancer Genetics and Genomics

Androgen Receptor Mutations Database

Atlas of Genetics and Cytogenetics in Oncology and Haematology

Ataxia-Telangiectasia Mutation Database

BRCA1

Breast Cancer Gene Database

Breast Cancer Information Core (BIC)

Disease-specific Cancer Chromosome Aberration Project (CCAP)

Human Cancer Gene Anatomy Project (CGAP)

Human Cancer GeneticsWeb

Human Chromosomal Abnormalities in Cancer

Human Gene Cards

Human Med. Gen. HotMolecBase

Human Med. Gen. cHmutDB

Human Med. Gen. Human Mutation Databases

Human Med. Gen. HUGO Mutation Database Initiative

Human Med. Gen. Human Gene Mutation Database (HGMD)

Human Med. Gen. The Mammary Transgene Database

Disease-specific Mouse Genome Database (MGD)

Mouse Tumor Biology Database (MTB)

MDM2 Database

Gene-specific NF1 GeneticMutation Analysis Consortium Web Site

Gene-specific Oncogenes and Tumor Supressor Genes in dbEST

On-line Mendelian Inheritance in Man (OMIM)

p53 Database

p53 Database (IARC)

p53 database (Human)

p53 Mutation Database Analysis \& Search (Human)

Prostate Expression Database (PEDB)

SAGEmap

The Tumor Gene Database

Universal Mutation Database Initiative

International Collaborative Group on Hereditary Non-Polyposis Colorectal Cancer

Mutation Database

VHL Mutation Database

WT1 Mutation Database http://ww2.mcgill.ca/androgendb/

http://www.infobiogen.fr/services/chromcancer/

http://www.vmresearch.org/atm.htm

http://bioinfo.weizmann.ac.il/hotmolecbase/entries/brca1.htm

http://condor.bcm.tmc.edu/ermb/bcgd/bcgd.html

http://www.nhgri.nih.gov/Intramural_research/Lab_transfer/Bic/

http://www.ncbi.nlm.nih.gov/CCAP/

http://www.ncbi.nlm.nih.gov/CGAP/

http://spade39.ncl.ac.uk/geneweb/

http://www.waisman.wisc.edu/cytogenetics/Bmproject/CancerCyto.htmlx

http://bioinformatics.weizmann.ac.il/cards/

http://bioinformatics.weizmann.ac.il/hotmolecbase/

http://www.ebi.ac.uk/mutations/central/

http://www.hgmp.mrc.ac.uk/GenomeWeb/human-gen-db-mutation.html

http://www2.ebi.ac.uk/mutations/cotton/

http://archive.uwcm.ac.uk/uwcm/mg/hgmd0.html

http://mbcr.bcm.tmc.edu:80/BEP/ERMB/mtdb.html

http://www.informatics.jax.org/

http://tumor.informatics.jax.org/

http://www.infosci.coh.org/mdm2asp/default.asp

http://www.nf.org/nflgene/nflgene.home.html

http://www.ncbi.nlm.nih.gov/dbEST/CancerGene.html

http://www3.ncbi.nlm.nih.gov:80/Omim/

http://perso.curie.fr/Thierry.Soussi/p53_databaseWh.htm

http://www.iarc.fr/p53/Index.html

hhttp://www.ibiblio.org/dnam/des_p53.htm

http://p53.genome.ad.jp/

http://www.pedb.org/

http://www.ncbi.nlm.nih.gov/SAGE/index.cgi

http://condor.bcm.tmc.edu/oncogene.html/

http://www.umd.necker.fr/UMD\%20Home.html

http://www.nfdht.nl/

http://www.umd.necker.fr:2005/

http://www.umd.necker.fr:2003/

Pathology

Comparative Pathology of Human and Mouse Breast Cancer NCI Veterinary Pathology

Transgenic Histopathology

A Tumor Atlas: Information, Resources, Images and Forms

Tumor Board http://www-p.ucdavis.edu/tgmice/cmpath/abstract.htm

http://www.ncifcrf.gov/vetpath/

http://www-mp.ucdavis.edu/tgmouse.html

http://bioscience.igh.cnrs.fr//atlases/tumpath/index.htm

http://www.tumorboard.com/ 
Database (http://pathbase.net). Details on mouse genetics and gene mapping (Silver, 1995; Sundberg et al., 1998) and access to mouse strains and mutations are readily available through the Mouse Genome Informatics Database (http://informatics.jax.org). These and many other resources are listed in Table 1.1.

This chapter provides an overview of methodologies commonly used to maintain, manipulate, and preserve genetic-based mouse models of human diseases, especially cancer models.

\section{METHODS FOR HANDLING LABORATORY MICE}

Each institution has its own regulations dealing with maintaining a rodent colony, which includes various types of housing, bedding, feed, and water. Regardless, it is critical to optimize these to maintain a pathogenfree colony. This includes autoclaving feed, acidifying or treating water to account for specific issues in each locality, and avoiding bedding that releases aromatic hydrocarbons that might complicate cancer studies. It is beyond the scope of this chapter to describe all the variations, but these are described elsewhere (Clark et al., 1996). Maintaining a pathogen-free colony, or at least a specific pathogen-free colony whereby the pathogen status is known for each colony, is critical as well. Controversy over complications of phenotypes due to pathogen status of colonies has dictated that careful and continual microbiological monitoring be incorporated into colony maintenance protocols. Again, it is beyond the scope of this chapter to describe diseasemonitoring selection and detection methods, but these are available (Lindsey et al., 1991a, b). This section will summarize some commonly used handling methods for mice to identify individuals as well as to collect bodily fluids and excretions.

Methods for individual identification of mice vary between institutions and laboratories. Some of the commonly used methods are summarized below (Seymour et al., 2004). All manipulations of mice require prior approval of the Institutional Animal Care and Use Committee (IACUC). Developing a good working relationship with the institutional attending veterinarian will be a great help in planning experiments, preparing documentation for IACUC protocol approval, and obtaining training in many of these procedures to optimize results.

\section{Identifying Individual Mice}

There are a number of methods that can be used for identification of individual mice in a colony or study. These range from ear notching using a small punch (National Band and TAg Company, Newport,
KY) to making a hole or notch in the mouse's ear (Figs. 1.1 and 1.2), ear tags (National Band and TAg Company) attached to the ear, digit amputation using scissors (Fig. 1.3), foot (Fig. 1.4) or tail tattooing using various tattooing machines (Animal Identification and Marking Systems, AIMS Inc., Ottawa, Canada), and implanting electronic chips under the skin of the mice (Bio Medic Data Systems, Inc., Seaford, DE, or American Veterinary Identification Devices, Norco, CA). Wounding mice can result in abnormal healing such as keloids or development of specific types of cancer in some models. Therefore, attention to methods that might complicate procedures is important.

\section{Collecting Blood and Body Fluids}

Blood is collected by retro-orbital bleeding, tail tip amputation, cardiac puncture, or decapitation. The reasons to use each method varies with age, purpose of the study, volume needed, and methods approved at each

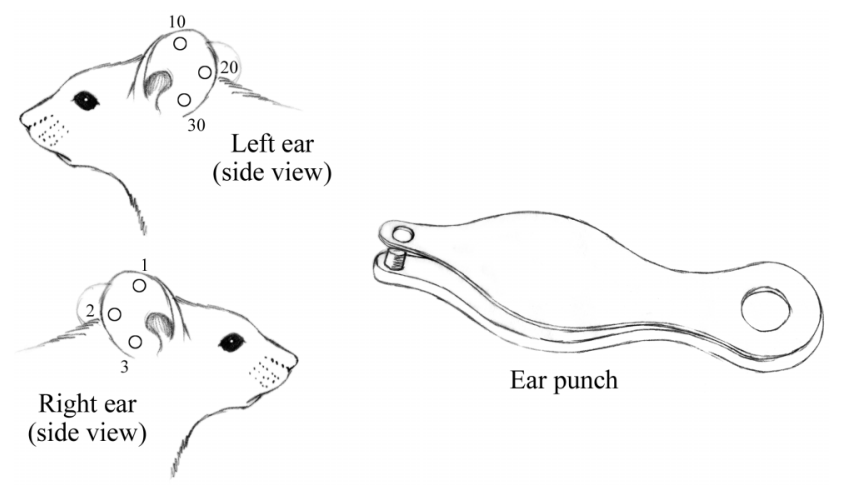

Figure 1.1. A small metal ear punch can be used to mark the ears of mice at specific locations to create a numerical code for individual mouse identification.

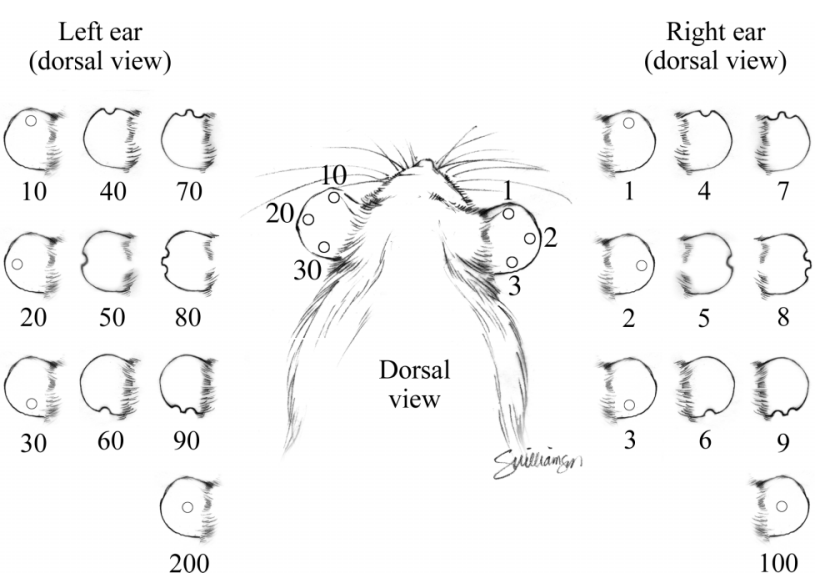

Figure 1.2. Dorsal view of a mouse showing commonly used numerical code approach for ear notching. 


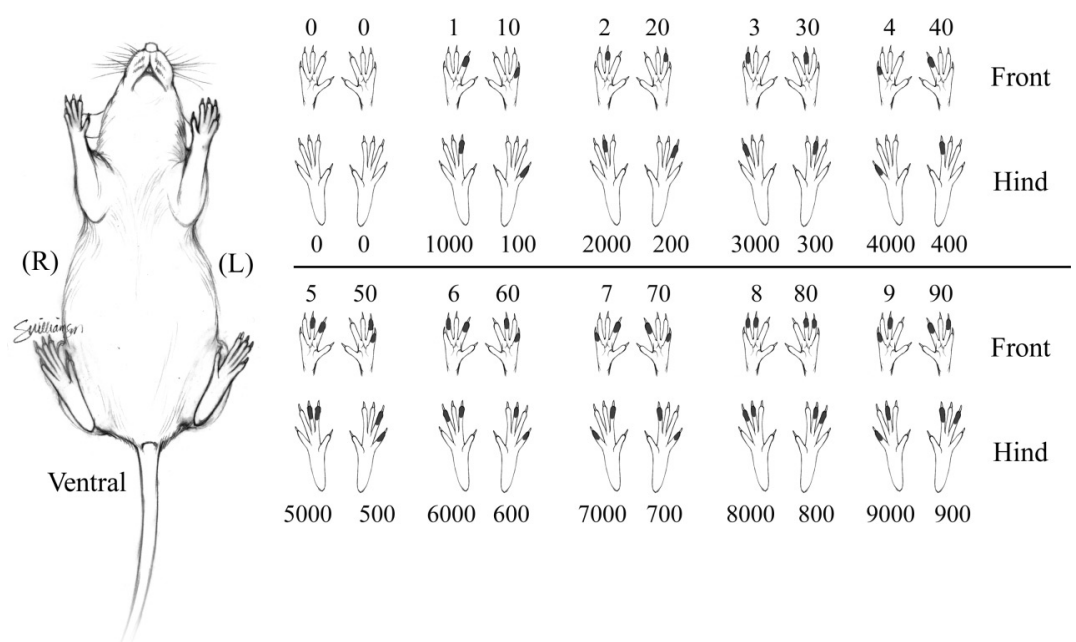

Figure 1.3. Ventral view of a mouse to orient feet. Digits can be amputated on neonatal mice as a form of numbering individuals.
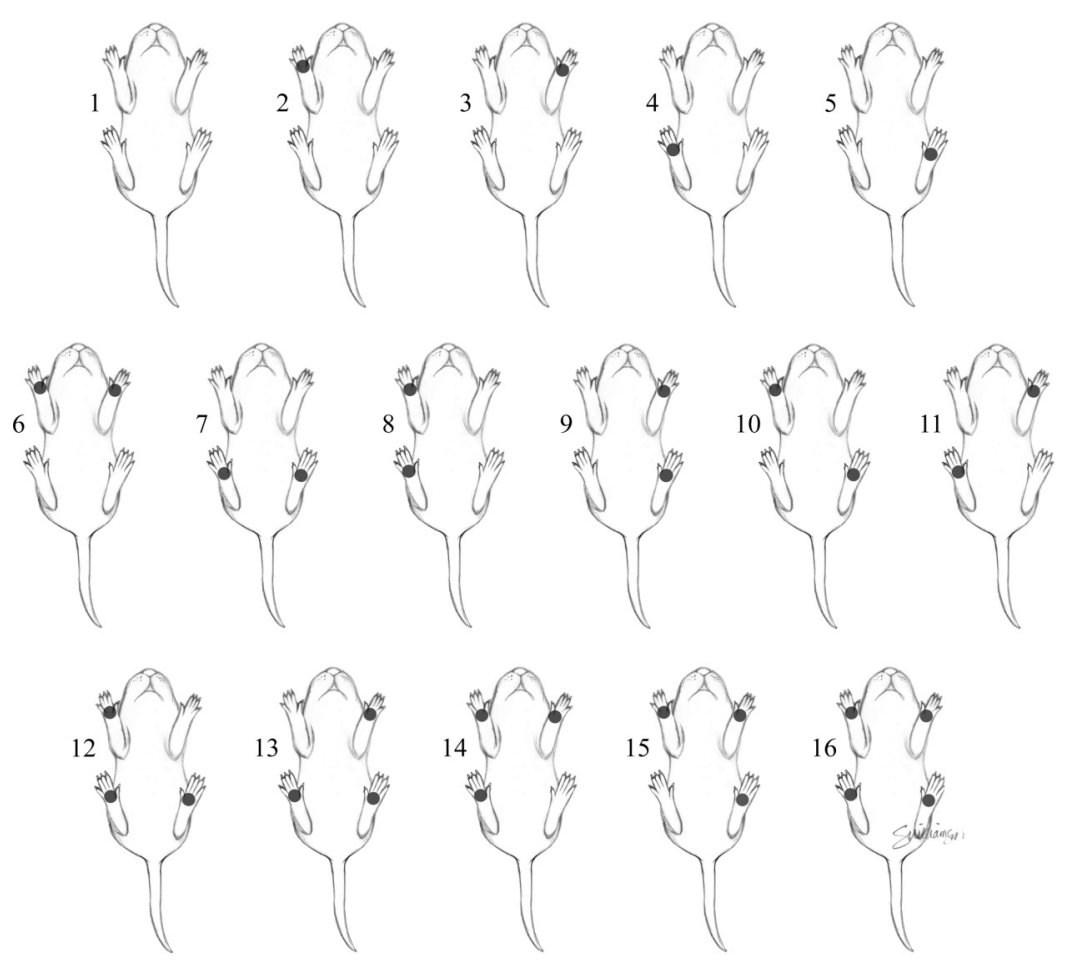

Figure 1.4. Tattoo ink can be injected into the skin at specific locations, as indicated, in neonatal mouse feet to create a numerical code to identify individuals.

institution. Methods are summarized below as modified from Seymour et al. (2004).

Retro-Orbital Bleeding This method is a valuable, nonterminal method for blood collection to obtain small volumes of blood. Retro-orbital bleeding is performed using manual restraint. Mice are grasped with thumb and index finger behind the ears placing the tail secured between the handlers' last finger and palm to immobilize them. A variety of anesthetics may be required by the IACUC at some institutions to perform this procedure.

The tip of an hematocrit tube is inserted into the medial canthus of the eye at a slight angle. Using a twisting motion with slight pressure on the tube, the retro-orbital 
venous plexus is entered. Once the blood begins flowing, the hematocrit tube should be withdrawn slightly to allow collection by capillary action. The hematocrit tube may be heparinized, contain ethylenediaminetetraacetic acid (EDTA), or other anticoagulants for plasma collection or contain no anticoagulant for serum collection.

Retro-orbital bleeding can also be used to collect larger volumes of blood if the mouse is going to be euthanized for necropsy. The mouse is anesthetized; then blood is collected in the same manner as for smaller volumes described above using heparinized hematocrit tubes. It is possible to fill 10-12 tubes using this method depending upon the size, age, and health status of the mouse. Each tube holds approximately $75 \mu \mathrm{L}$ of blood. These tubes can be expressed into the appropriate collection tubes for the types of testing being done (see section on blood handling). This method decreases the variability in test results that may be caused by stress the mouse suffers during other methods of blood collection. This method also allows for more uniformity in sample volume when working with many mice.

Tail Bleeding Some technicians hold the mouse as described for the eye bleed for a manual tail bleed procedure. However, tail bleeding is often done when the mouse is placed in a restraint device with the tail protruding with an Eppendorf or glass tube for blood collection positioned below it (Fig. 1.5). Care must be taken not to contaminate blood with fecal matter or urine when using the tail-bleeding method. A tail bleed is accomplished by severing the ventral coccygeal vein on the ventral side of the base of the tail with a razor blade. Warming the mouse or its tail prior to bleeding will increase the blood flow.

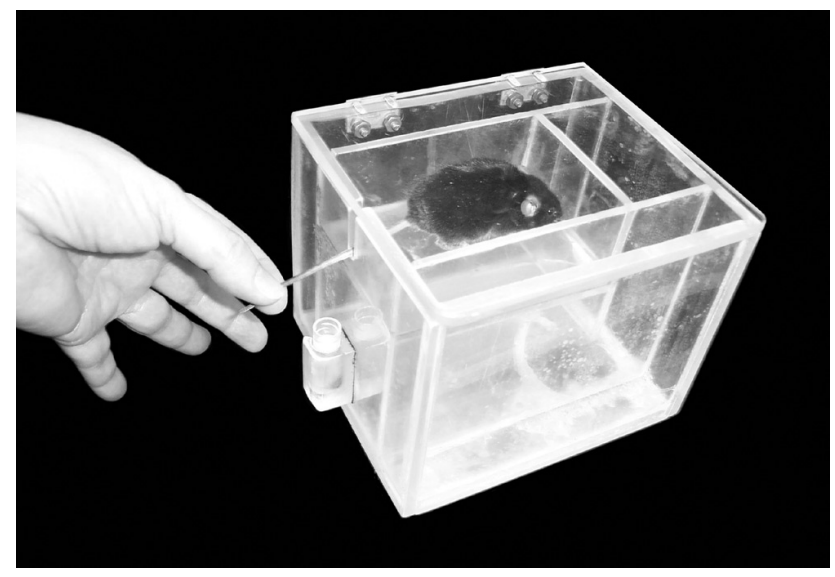

Figure 1.5. A plastic restraint device can be used to collect blood from the tail. Note the tube holder and collecting tube below the tail.
Cardiac Puncture Cardiac puncture is a clean and simple way to get as much blood as possible from a mouse at the time of necropsy. It must be performed immediately after the mouse is euthanized. Many people perform cardiac puncture without opening up the thorax by inserting a 25 - to 27 -gauge needle through the skin and intercostal muscles and into the heart, then withdrawing blood into the syringe (a 1-mL syringe is large enough for most mice). This approach requires some technical skill but often results in sufficient amounts of blood being obtained. An alternative approach is to open the thoracic cavity immediately after euthanizing the mouse. This will expose the heart, making it easy to correctly insert a needle, obtaining a cleaner sample of larger volume. This is achieved by following normal necropsy procedures detailed elsewhere (Relyea et al., 2000; Seymour et al., 2004), being careful not to sever major blood vessels. Once the abdominal muscles have been incised, a pair of sharp/sharp scissors is used to cut the ribs in a triangular shape, starting equidistant from the xiphoid process on both sides and angling toward the clavicle. The sternum should not be severed since this may rupture major blood vessels near the thoracic inlet, causing rapid and excessive blood loss. The ribs should be retracted to reveal the heart and lungs. Using this approach, the right ventricle can be visualized and cleanly punctured. Blood is withdrawn slowly into the syringe. Gentle pressure applied to the visceral organs, working toward the heart, pushes abdominal blood into the right ventricle to optimize collection. Blood should be promptly and gently expressed into an appropriate collection tube before clotting occurs. The syringe plunger should be depressed slowly since high-velocity ejection may damage red blood cells, resulting in hemolysis.

Decapitation This method is seldom approved by animal-care-and-use committees unless there is sound scientific justification. This is the method of choice for some endocrine assays when hormones may be released during handling, altering results, or for mice less than 10 days old. A number of commercial guillotine-type instruments are available (Harvard Apparatus Inc., Holliston, MA). Alternatively, mice can have their heads disarticulated with a large pair of scissors (6.5-7 in., blunt/sharp). The mouse is firmly grasped by the skin at the back of the neck and, holding it over a blood collection tube, the head is swiftly and cleanly severed.

\section{Blood Handling}

For serum collection, blood should be collected into smallvolume serum separator tubes (Microtainer Brand, stock number 365956, Becton Dickinson, Franklin, NJ). These can then be held at room temperature for $15 \mathrm{~min}$ to 
$1 \mathrm{~h}$ and then centrifuged. The serum should be decanted and stored in plastic tubes (Eppendorf tubes, Brinkmann Instruments, Inc., Westbury, NY; Nunc Tubes, Nalge Nunc International, Fisher Scientific, Pittsburgh, PA) for storage and frozen at $-80^{\circ} \mathrm{C}$ until used. Plasma is obtained by collecting blood in tubes containing EDTA or heparin to prevent clotting. The blood is then centrifuged, the plasma is decanted into tubes, and it is frozen for future use. Whole blood should be handled according to the instructions provided by the diagnostic laboratory that will be doing the blood chemistry workup.

\section{Feces}

Feces are collected at the time of necropsy and can be frozen in plastic tubes for a variety of assays. Most mice defecate upon handling so a few fresh samples can be obtained from a defined individual. This is a simple resource for Helicobacter spp. surveillance using polymerase chain reaction (PCR) methods (Mahler et al., 1998) or for fecal IgA quantification (Bristol et al., 2000).

\section{Urine}

Urine is usually expelled when a mouse is handled. A person can pick up the mouse as described for the retroorbital bleeding procedure, holding the tail back with the little finger. In this position most mice micturate a few drops of urine. If needed, the mouse can be manually restrained and the caudal abdomen gently massaged to induce urination. Urine can be collected in a clean plastic tube or tests done directly with a variety of chemically impregnated strips. Chemstrip (Boehringer Mannheim Diagnostics, Indianapolis, IN) and Ames Multistix (Miles Inc. Diagnostic Division, Tarrytown, NY) are two urine analysis reagent strips that test for numerous urine components, including glucose, ketones, protein content, and $\mathrm{pH}$. For more specific tests that require larger volumes of urine or urine collected over defined intervals, metabolic cages are commercially available (Columbus Instruments, Columbus, $\mathrm{OH}$ ). Urine specific gravity is measured using a hand-held refractometer. Some companies offer refractometers especially made for urine testing, such as the Fisherbrand UriSystem Refractometer (Fisher, Pittsburgh, PA).

\section{GENERAL BREEDING STRATEGIES FOR MAINTAINING COLONIES OF GENETICALLY ENGINEERED MICE}

When establishing a colony of potentially mutant mice, it is important to examine all mice as soon after birth as possible and at regular intervals (at least every other day during the first 2 weeks) thereafter until the phenotype (clinical features) are well defined. Defects may be observable at birth, as is seen in flaky skin $(f s n)$ mice, which have a mild anemia at birth, that make them easy to identify (Sundberg et al., 1997b) or juvenile alopecia (jal) mice, which have easily identifiable abnormalities of the vibrissae as early as 2-3 days of age (McElwee et al., 1999). Other defects may develop as the mouse ages, as in harlequin ichthyosis (ichq), in which mice are normal until 5 days of age, when they develop thick scaling skin, then die by 10-12 days of age (Sundberg et al., 1997a); matted $(m a)$, in which the hairs form matted clumps and mutants can be identified at 2-4 weeks of age (Sundberg, 1994c); and chronic proliferative dermatitis (cpdm), in which the skin lesions become apparent at 4-6 weeks of age (HogenEsch et al., 1993). Some defects may even disappear as the animal ages, as with flaky tail $(f t)$, in which the skin defect is recognizable by $2-4$ days of age and has usually disappeared and appears to be normal by 14-15 days of age (Presland et al., 2000; Sundberg, 1994a)

Establishing a colony of the suspected mutation is best done by obtaining the parents of the deviant pup or litter and allowing them to continue to produce litters. If the parents are unavailable or are too old to produce more litters, the siblings of the affected mouse can be mated together to produce more litters. If any of the offspring of the parental or sibling matings produce more of the phenotype in question, then it is possibly a genetic mutation.

When you have determined that the phenotype is reproducible, you can expand the colony. At this time you will also want to do a systematic diagnostic necropsy of at least one mutant and one normal littermate. This is to further rule out the possibility of infectious disease as well as to attempt to identify the disease processes that are causing the phenotype of the deviants. This will allow you to better direct the characterization and maintenance of the colony.

The colony can be expanded by simple brother-bysister crosses. Matings of this type would be considered unknown test matings. If any of these matings produced at least one affected offspring in a litter, then the animals in that mating would be considered tested breeders. Matings are usually maintained until at least $18-20$ pups are born, with no deviants found, before being deemed a negative test mating. Nonproductive breeders and breeders that produce no affected offspring should be remated to tested breeders or removed from the colony.

If recessive mutant mice can breed, it is a good idea to breed homozygous $(\mathrm{m} / \mathrm{m} ; \mathrm{m}=$ mutant $)$ mutants to heterozygous $(+/ m)$ or wild-type $(+/+)$ litter mates. With these types of matings your are assured of getting litters that will either have some homozygous, affected mice 
and some heterozygous, normal mice or, if none are affected, all heterozygous mice. There are some mutations, which, due to the phenotype, make the females poor mothers. Lethal milk mutation is an example of this type of mutation (Piletz and Ganschow, 1978a, b). For this reason it is usually best to mate mutant males to normal (heterozygous or wild-type) females.

In cases where the mutant mice do not breed, die in utero, or die soon after birth, it may be possible to expand and maintain the colony by use of ovarian transplantation. Ovaries from mutant mice are transplanted into oophorectomized, histocompatible recipients or severe combined immunodeficiency mutation $\left(P r k d c^{s c i d} / P r k d c^{\text {scid }}\right)$ recipients that will accept grafts from nonhistocompatible strains (Boggess et al., 2000). These recipient females are then mated to homozygous mutant (if they can breed) or tested heterozygous males. This type of mating will produce litters the same as those mentioned above. When choosing the option of ovarian transplantation, one must remember to choose a recipient mouse that will enable you to verify that all the offspring born are indeed from the donated ovary and not from any chance remnant of ovary from the recipient mouse. This is usually done using a coat color marker. For example, when transplanting ovaries from a black mouse into a white (albino) recipient, any white offspring born would indicate the presence of ovarian remnants from the albino mouse. If a $P r k d c^{\text {scid }} / P r k d c^{\text {scid }}$ mutation is used as the recipient, you must be able to house this strain in a relatively pathogen-free environment and provide antibiotic treated water for part of each week. SulfaTrim (sulfamethoxazole and trimethoprin oral suspension, USP, Schein Pharmaceutical Inc., Florham, NJ), $10-15 \mathrm{~mL} / 400 \mathrm{~mL}$ acid water, is commonly used (Shultz et al., 1989). The antibiotic water is put on the cages on alternate weeks with untreated acidified water. This is usually sufficient to keep the mice healthy. The immunodeficient recipient mice should not be kept on the antibiotic water continually since this will cause the microflora to develop resistance to the antibiotic.

Another method of expanding and maintaining the colony if the mutant mice have reduced viability or if the mutation was originally found on a segregating (outbred) background is to create a congenic strain by outcrossing the strain carrying the mutation (donor strain) with another inbred strain (recipient strain). By selecting mice homozygous (if fertile) or heterozygous for the mutation and outcrossing these animals to the recipient strain and then selecting affected offspring to backcross to the recipient strain, it is possible to "transfer" the mutation onto the selected inbred strain, thereby creating a new congenic strain (Silver, 1995). Creation of the congenic strain and the subsequent inbreeding done after the congenic is created can make profound changes to the phenotype as observed in the original mutation. Therefore, it is important to collect tissues for histology from animals with the original mutation for comparison with tissues from the congenic mice created to verify that the original phenotype was not lost or significantly changed.

Another important aspect of mutant mouse evaluation and colony management is the setting up of matings for genetic mapping purposes. If you are working with a mutant mouse colony with a phenotype that resembles another mutation which has already been characterized and mapped, you can save time by doing simple allelism tests (complimentation assays) between your mutant and any other mutant that it resembles. This type of testing is done by mating a homozygous or known heterozygous mouse with a known, characterized, and mapped mutation to a homozygous or known heterozygous mouse carrying the new mutation. If a mating between these animals produces offspring in the first generation with the same phenotype as both parents, it can then be interpreted that the new mutation is a remutation or allele (noncomplimentation) of the known mutation. This type of test is simple if the mutation is recessive but becomes much more complicated for a dominant mutation.

Setting up matings for interspecific and intersubspecific crosses, needed for gene mapping, comes with its own set of problems in colony management. Mus musculus castaneous (CAST/EiJ) mice are much more aggressive than most common inbred strains of mice and are known to kill mice smaller than themselves if the mice are introduced to each other much after weaning age (approximately 3 weeks of age). This is true of both males and females. CAST/EiJ mice are also slow to reach sexual maturity. A mating between two CAST/EiJ mice or a CAST/EiJ male and a female of another strain may not produce their first litter until the mating has been together for as long as 3 months. It is important not to deem a mating "nonproductive" until at least this amount of time has passed. Female CAST/EiJ mice mated to older males of another strain may have their first litter sooner than three months, but again it is important not to discontinue the mating too soon. An increased success rate in starting a colony of mutant $\times$ CAST/EiJ crosses can be achieved by using CAST/EiJ females mated to mutant or known heterozygous males rather than vice versa.

\section{GENOTYPING GENETICALLY ENGINEERED MICE}

Genotyping mutant mice, whether they be genetically engineered or spontaneous mutations, has become progressively easier as spontaneous mutations have been defined and protocols standardized for molecular 
assays. Protocols can be found on various websites (http://jaxmice.jax.org/info/index.html) or in the original papers that describe the constructs and genotyping used to create the model. Most of these methods utilize PCR methods with primers designed to detect the Neo cassette insert for targeted mutations, specific sequence changes within the mutated genes, restriction length polymorphisms with or without the use of Southern blots, or quantitative real-time PCR methods. Some mutations are easier to phenotype that to genotype. For example, immunodeficient mutant mice may be easier in some studies to phenotype by blood smear, fluorescence-activated cell sorter analysis, or other methods. The easiest way to proceed is to find a website that provides detailed protocols and information on primers and restriction sites used to genotype mice and follow those protocols. Some genetically engineered mice, such as B6.129P2-Ncam ${ }^{t m 1 C g n}$, can be quite difficult to genotype. Contacting the laboratory directly is sometimes warranted to learn specific protocols needed. Details on running the various assays are provided in standard methodology textbooks (Jackson and Abbott, 2000).

\section{CRYOPRESERVATION OF EMBRYOS, SPERM, AND MOLECULAR CONSTRUCTS}

Investigators who have produced a genetically engineered mouse strain useful as a model for human cancer and completed and published their experiments are faced with the question of what to do with these mice. On the one hand, these mice, which were produced with a significant investment of time and resources, might once again become a critical research tool as the field progresses. On the other hand, mice are expensive to maintain and animal facilities are often space limited, creating pressure to discard the animals. The solution is to cryopreserve the strain. This also provides security against loss of the strain through accident, disaster, malfeasance, genetic contamination, or disease. Cryopreservation also archives the genome of the mice, providing a kind of "genetic vintage" of a genome that will prevent change with time due to genetic drift.

Several repositories and distribution centers have been created worldwide that will accept, maintain, and distribute strains of mice at no cost to the donating investigator if oversight committees determine that these strains have potential future scientific value (Table 1.2). These repositories all cryopreserve the strains they accept as a matter of course, not only for the security this provides, but also because they too have only limited carrying capacity for mouse strains. In fact, a significant percentage of their inventories are held as cryopreserved material and not as live mice. Unfortunately, these repositories do not have the capacity to accept all the strains that are submitted to them.

The purpose of this section is to provide an overview of the requirements and considerations for cryopreserving one's own mouse strains. Explicit protocols are beyond the scope of this chapter, but they can be obtained from laboratory manuals (Nagy, 2002) or on the Web (The Jackson Laboratory Cryopreservation Resource, http://www.jax.org/cryo/index.html).

A major prerequisite for mouse strain cryopreservation is the ability to manipulate mouse embryos. These techniques include collecting embryos from superovulated donors, maintaining them in culture, and surgically transferring them to pseudopregnant foster mothers. The cryopreservation of mouse germplasm involves the following steps:

1. Collection of the material

2. Suspension in a concentrated nonphysiologic solution of cryoprotectant

Table 1.2. Mutant Mouse Repositories

\begin{tabular}{llc}
\hline Repository & \multicolumn{1}{c}{ Maintained By } & Web Site \\
\hline $\begin{array}{l}\text { Mouse Models of Human } \\
\text { Cancers Consortium } \\
\text { (MMHCC) }\end{array}$ & National Cancer Institute & http://emice.nci.nih.gov/ \\
$\begin{array}{l}\text { Induced Mutant Resource } \\
\text { (IMR) }\end{array}$ & $\begin{array}{l}\text { The Jackson Laboratory, Bar Harbor, Maine, } \\
\text { Uutant Mouse Regional }\end{array}$ & http://www.jax.org/imr/index.html \\
Resource Centers (MMRRC) & $\begin{array}{c}\text { National Center for Research Resources } \\
\text { University of California, Davis; University }\end{array}$ & http://www.mmrrc.org/ \\
& of North Carolina, Chapel Hill; Taconic & \\
& Farms-University at Albany SUNY; Harlan & \\
European Mouse Mutant & Sprague Dawley-Missouri Consortium & http://www.emmanet.org/ \\
Archive (EMMA) & European Commission Framework & Programmes and various institutions \\
MRC Frozen Embryo \& Sperm & Mammalian Genetics Unit, Medical Research & http:/www.mgu.har.mrc.ac.uk/fesa/fesa.html \\
Archive (FESA) & Council, Harwell UK. & \\
\hline
\end{tabular}


3. Cooling to a low subzero temperature in a way that the cells lose all intracellular water, thus avoiding the formation of intracellular ice that would physically disrupt the cells

4. Storage in liquid nitrogen

5. Warming to physiologic temperatures

6. Removing the cryoprotectant without damage due to osmotic shock or toxicity of the cryoprotectant

7. Production of live animals

The first consideration in cryopreserving a strain of mice is the choice of material to freeze. Embryos, sperm, and ovaries have all been frozen successfully. Less commonly, because they are technically difficult to deal with, oocytes and spermatogonia have also been successfully cryopreserved. Of these forms of germplasm, embryos have the advantage that they preserve the diploid genome of the strain of mice. Thus, the strain is regenerated by the direct recovery of live pups from the frozen embryos. The other forms of preserved haploid germplasm can only produce heterozygous or hybrid offspring unless sperm or oocyte donors of the same strain are available for fertilization with the frozen gametes. Since this is not usually practical, embryo cryopreservation is the best choice for inbred or congenic strains. In practical terms, this means that embryo cryopreservation is the only choice for inbred and congenic lines of mice. The other choices are only appropriate if one is not interested in preserving the genetic background but only the mutation or if one is reasonably confident that mice of the appropriate genetic background will always be available to act as sperm or oocyte donors for recovery.

Mouse embryos were first successfully cryopreserved in 1972 (Whittingham et al., 1972). Since then, many different protocols using a variety of cryoprotective agents, cooling rates, and storage containers have been published that permit the cryopreservation of mouse embryos at all preimplantation stages. Most of these work quite well, and the method chosen is simply a matter of personal preference. One method is outlined in Table 1.3. Recovery of pups is accomplished by the surgical transfer of embryos into pseudopregnant foster mothers, who carry them to term.

Sperm cryopreservation is a more recent development, and the most commonly used protocol was developed by Nakagata (Nakagata and Takeshima, 1993). In cases where a suitable oocyte donor is expected to be available, it is an attractive method for preserving a strain because it is extremely easy (sperm are collected from the vas deferentia and epididymides into a solution of $18 \%$ raffinose and 3\% nonfat dried milk, cooled for $10 \mathrm{~min}$ at approximately $-110^{\circ} \mathrm{C}$ in the vapor phase of a liquid nitrogen storage tank, and plunged into liquid nitrogen). In addition, a single male produces a large amount of material (approximately $3 \times 10^{7}$ sperm). Recovery requires in vitro fertilization to produce embryos, which again are transferred to foster mothers to produce pups. The major drawback of this method, however, is that sperm from many inbred strains of mice, in particular C57BL/6 and 129, lose their ability to fertilize after freezing. Recovering pups at a reasonable efficiency requires manipulating the oocyte to disrupt the zona pellucida or using the technically difficult technique of intracytoplasmic sperm injection to fertilize the oocyte.

Ovary cryopreservation can be accomplished using a modification of an embryo-freezing protocol. Ovaries are collected from young females, cut in half, and frozen. One recovers live mice from this material by doing an ovarian transplant. This requires a histocompatible, immunosuppressed, or immunodeficient recipient host for the thawed ovary. Furthermore, a suitable sperm donor must be available to mate with the transplant recipient.

The amount of material one cryopreserves is driven in part by how often one expects to recover material. The large repositories typically store enough material to provide for 10 recoveries and restock a strain long before they consume all the frozen samples. Typically, this means 250-500 carrier embryos, at least a dozen vials of frozen sperm, or ovaries from 20 donors. An individual laboratory that is simply archiving a strain for personal use can reduce these amounts accordingly.

It is important to do a number of controls when cryopreserving a strain of mice. The first is to assure that one is able to recover live pups from the frozen material before discarding the colony of live mice. Second, when freezing embryos, it is wise to freeze a vial of control embryos on each day that archived embryos are frozen. The control embryos can then be thawed and cultured to the blastocyst stage to ensure that each day's freeze was successful.

Frozen material will last indefinitely at liquid nitrogen temperatures with no loss of viability over time. Thus, samples will recover with the same survival rate whether they are stored for minutes or for years. However, samples must be kept cold. Liquid nitrogen storage is relatively inexpensive but requires that the storage containers are always supplied with liquid nitrogen. Mechanical freezers avoid the necessity of maintaining a liquid nitrogen supply but are subject to mechanical failure or power loss. Some method of monitoring and logging temperature and, for liquid nitrogen, liquid levels is a good idea. Another good idea is to split samples between multiple storage containers. It is even better if one of these storage containers is in a physically separate space, ideally offsite.

Because of the advantages that cryopreservation provides in conserving mouse colony resources and protecting valuable strains against loss, cryopreservation is becoming more common as a service provided by institutional transgenic core facilities. It is also 
Table 1.3. Mouse embryo cryopreservation protocol. This is the protocol used by the Jackson Laboratory Cryopreservation Resource to freeze 2-cell through 8-cell mouse embryos. It is a modification of the method published by Renard and Babinet (1984)

A. Freezing method.

1. Embryos are held in M2 medium at room temperature until ready for addition of cryoprotectant.

2. $0.25 \mathrm{ml}$ semen straws are prepared as follows:

a. Push the cotton/PVA plug into the straw until it is $75 \mathrm{~mm}$ from the end.

b. Mark the straw $20 \mathrm{~mm}, 27 \mathrm{~mm}$ and $32 \mathrm{~mm}$ from the plug with an alcohol-proof marking pen

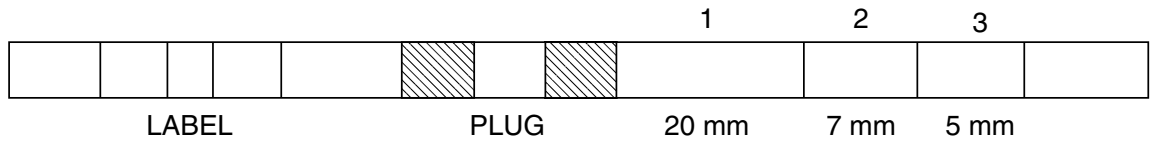

c. Aspirate 1.0 M sucrose in M2 into the straw until it reaches mark 3.

d. Aspirate air so that the sucrose meniscus reaches mark 2.

e. Aspirate $1.5 \mathrm{M}$ propanediol $(\mathrm{PROH})$ in $\mathrm{M} 2$ until the sucrose meniscus reaches mark 1.

f. Aspirate air until the sucrose column forms a seal with the plug.

3. Transfer the embryos into a drop of $1.5 \mathrm{M} \mathrm{PROH}$ in $\mathrm{M} 2$ and equilibrate for 15 minutes

4. Transfer the embryos into the PROH drop in the straw. This can be done under a dissecting microscope.

Take care to avoid transferring a large amount of medium and large air bubbles along with the embryos. 25 embryos is a reasonable number to store in each straw.

5. Seal the straws using Critoseal.

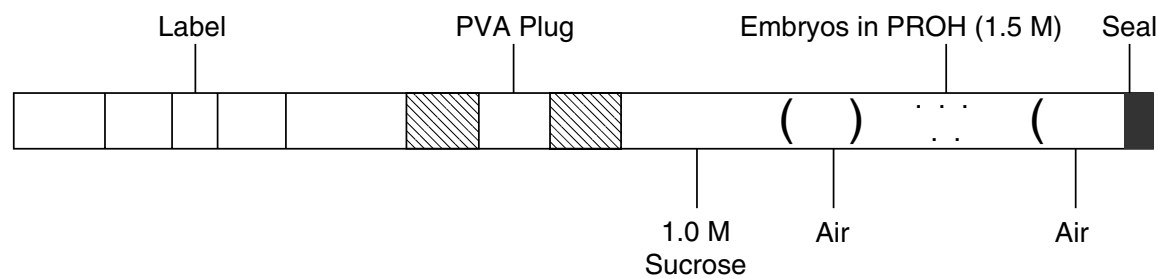

6. Place loaded straws into a controlled-rate alcohol bath freezer at $-7^{\circ} \mathrm{C}$ so that the embryo-containing ends are submersed in the alcohol and equilibrate for 5 minutes.

7. Seed ice formation by touching the straws outside the sucrose column near the cotton plug with a cotton swab dipped in liquid nitrogen.

8. Wait 5 minutes and check that ice has migrated down into the embryo fraction. Re-seed straws if necessary.

9. Cool the straws at $0.5^{\circ} \mathrm{C} /$ minute until the temperature has reached $-30^{\circ} \mathrm{C}$.

10. Transfer the straws to liquid nitrogen for storage.

B. Thawing embryos

1. Transfer the straws from the liquid nitrogen storage freezer to a smaller container of liquid nitrogen

2. Grasp the straw near the label with forceps and hold in air for 40 seconds, then in room temperature water until the ice disappears.

3. Wipe the straw dry

4. Cut off the seal and cut through the PVA plug, leaving about half the cotton plug to act as a plunger. Use a metal rod to expel the contents into a Petri dish.

5. Wait 5 minutes. The embryos will shrink considerably as water and the PROH diffuse out.

6. Transfer the embryos to a drop of M2. The will rapidly assume a normal appearance as water diffuses back in.

7. Wash the embryos in fresh M2 and transfer to a pseudopregnant recipient or culture in KSOM medium. 
commercially available from most of the large mouse vendors. Finally, comprehensive training in cryopreservation techniques is offered by The Jackson Laboratory (http://www.jax.org/courses/index.html) and by the European Mutant Mouse Archive (http://www.emmanet.org).

\section{DRUG ADMINISTRATION IN LABORATORY MICE}

Creation and characterization of mouse models for specific types of human cancer are the focus of most of the initial research in model development. The real value of many of these models is when they can be used to validate current treatments in human patients and then to test novel therapeutic approaches. Administration of drugs requires IACUC approval prior to testing. A number of methods are commonly used and are summarized below.

\section{Intravenous Injections}

The ventral coccygeal vein of the mouse tail is a common site for intravenous injections. The mouse is generally placed in a restraint device with the tail protruding. Warming the mouse or its tail will increase the flow of blood. Small-gauge $(30 \mathrm{~g})$ needles are used on syringes through the skin and into the vein.

\section{Subcutaneous Injections}

The mouse has very loosely attached skin that can be lifted and a small-gauge needle is inserted into the flap of skin over the back and neck once it is raised digitally.

\section{Intradermal Injections}

This method is similar to subcutaneous injections except the needle is positioned within the layers of the skin instead of through the skin. Mouse skin is extremely thin so this method is almost impossible to perform.

\section{Intramuscular Injections}

Generally, intramuscular injections, as in larger types of laboratory animals, are made with small-gauge needles into the epaxial muscles on either side of the spinal column or the quadricepts muscles of either rear leg. Due to the small size of mice, very small volumes should be injected.

\section{Intralesional Injections}

Small-gauge needles can be used on syringes to inject drugs into a neoplastic mass. The volume depends upon the size and number of the lesions.

\section{Intraperitoneal Injections}

The mouse is manually restrained with the head and body tilted downward. A small-gauge needle is inserted into the caudal left abdominal quarter, thereby avoiding injection into the cecum on the right side.

\section{Osmotic Pumps}

Osmotic pumps (ALZET Osmotic Pumps, Durect Corp., Cupertino, CA) can be surgically implanted subcutaneously or intraperitoneally to transport drugs over prolonged periods of time.

\section{Slow-Release Subcutaneous Implants}

Silastic capsules, consisting of $10-\mathrm{mm}$ silastic tubing (Dow-Corning Corp., Midland, MI) packed with the drug or hormone and having the ends sealed with 3-mm glass beads, can be implanted through a small incision over the dorsal thoracic midline in the subcutaneous tissues.

\section{CONCLUSIONS}

In summary, identifying genetically engineered mice as models for human cancers, establishing and preserving colonies of these mice, and experimental manipulation of the mice with various therapeutic regiments are routine in many rodent facilities today. Understanding the basic approaches described in this chapter provides investigators with a working knowledge of the options available to address their specific research questions. Working with their institutional attending veterinarian assures that these methods will be used in a humane manner and meet IACUC requirements for the institution.

\section{ACKNOWLEDGMENTS}

This work was supported by grants from the National Institutes of Health (RR179, CA89713, and CA34196). The authors thank S. Williamson for the graphics and N. D. Buckley for assistance with the tables.

\section{REFERENCES}

Boggess D, Cunliffe-Beamer TL, Sundberg JP (2000): Colony establishment. In Boggess D (Ed), Systematic Approach to Evaluation of Mouse Mutations. CRC, Boca Raton, FL, pp $1-13$.

Bristol IJ, Farmer MA, Cong Y, Zheng XX, Strom TB, Elson CO, Sundberg JP, Leiter EH (2000): Heritable susceptibility for colitis in mice induced by IL-10 deficiency. Inflamm Bowel Dis 6: 290-302.

Clark JD, Baldwin RL, Bayne KA, Brown MJ, Gebhart GF, Gonder JC, Gwathmey JK, Keeling ME, Kohn DF, Robb JW, Smith OA, Steggerda JAD, Vandenbergh JG, White WJ, Williams-Blangero S, VandeBerg JL (1996): Guide for the Care and Use of Laboratory Animals. National Academy Press, Washington, DC.

HogenEsch H, Gijbels M, Offerman E, Hooft Jv, Bekkum Dv, Zurcher C (1993): A spontaneous mutation characterized by 
chronic proliferative dermatitis in C57BL mice. Am J Pathol 143: 972-982.

Jackson IJ, Abbott CM (2000): In Hames BD (Ed), Mouse Genetics and Transgenics. Oxford University Press, New York.

Lindsey JR, Boorman GA, Collins MJ, Hsu C-K, VanHoosier GL, Wagner JE (1991a): Companion Guide to Infectious Diseases of Mice and Rats. National Academy Press, Washington, DC.

Lindsey JR, Boorman GA, Collins MJ, Hsu C-K, VanHoosier GL, Wagner JE (1991b): Infectious Diseases of Mice and Rats. National Academy Press, Washington, DC.

Mahler M, Bedigian HG, Burgett BL, Bates RJ, Hogan ME, Sundberg JP (1998): Comparison of four diagnostic methods for detection of Helicobacter species in laboratory mice. $L a b$ Anim Sci 48: 85-91.

Maronpot RR, Boorman GA, Gaul BW (1999): Pathology of the Mouse. Reference and Atlas. Cache River, Vienna, IL.

McElwee KJ, Boggess D, King LE, Sundberg JP (1999): Alopecia areata versus juvenile alopecia in $\mathrm{C} 3 \mathrm{H} / \mathrm{HeJ}$ mice: Tools to dissect the role of inflammation in focal alopecia. Exp Dermatol 8: 354-355.

Mikaelian I, Nanney LB, Parman KS, Kusewitt DF, Ward JM, Naf D, Krupke DM, Eppig JT, Bult CJ, Seymour R, Ichiki T, Sundberg JP (2004): Antibodies that label paraffin-embedded mouse tissues: a collaborative endeavor. Tox Pathol 32: $181-191$.

Mikaelian I, Ichiki T, Ward JM, Sundberg JP (2004): Diversity of spontaneous neoplasms in commonly used inbred strains and stocks of laboratory mice. In Hedrich HJ (Ed), Handbook of Experimental Animals: The Laboratory Mouse. Academic Press, London, pp. 345-354.

Mohr U, Dungworth DL, Capen CC, Carlton WW, Sundberg JP, Ward JM (1996): Pathobiology of the Aging Mouse. ILSI, Washington, DC.

Nagy A (2002): Manipulating the Mouse Embryo, 3rd ed. Cold Spring Harbor Laboratory, Cold Spring Harbor, NY.

Nakagata N, Takeshima T (1993): Cryopreservation of mouse spermatozoa from inbred and F1 hybrid strains. Jikken Dobutsu 42: 317-320.

Nakamura M, Sundberg JP, Paus R (2002a): Mutant laboratory mice with abnormalities in hair follicle morphogenesis, cycling, and/or structure: annotated tables. Exp Dermatol 10: 369-390.

Nakamura M, Tobin DJ, Richards-Smith B, Sundberg JP, Paus R (2002b): Mutant laboratory mice with abnormalities in pigmentation: annotated tables. J Dermatol Sci 28: 1-33.

Piletz JA, Ganschow RE (1978a): Lethal milk mutation results in dietary zinc deficiency in nursing mice. Am J Clin Nutr 31: $560-562$.

Piletz JE, Ganschow RE (1978b): Zinc deficiency in murine milk underlies expression of the lethal milk (lm) mutation. Science 199: 181-183.

Presland RB, Boggess D, Lewis SP, Hull C, Fleckman P, Sundberg JP (2000): Loss of normal profilaggrin and filaggrin in flaky tail $(f t / f t)$ mice: An animal model for the filaggrin-deficient skin disease ichthyosis vulgaris. J Invest Dermatol 115: 1072-1081.

Relyea MJ, Miller J, Boggess D, Sundberg JP (2000): Necropsy methods for laboratory mice: Biological characterization of a new mutation. In Boggess D (Ed), Systematic approach to evaluation of mouse mutations. CRC, Boca Raton, FL, pp 57-90.

Renard JP, Babinet C (1984): High survival of mouse embryos after rapid freezing and thawing inside plastic straws with 1-2 propanediol as cryoprotectant. J Exp Zool 230: 443-448.

Seymour R, Ichiki T, Mikaelian I, Boggess D, Silva KA, Sundberg JP (2004): Necropsy methods. In Hedrich HJ (Ed), Handbook of Experimental Animals: The Laboratory Mouse. Academic Press, London, pp. 495-516.

Shultz LD, Schweitzer PA, Hall EJ, Sundberg JP, Taylor S, Walzer PD (1989): Pneumocystis carinii pneumonia in scid/scid mice. Curr Topics Microbiol Immunol 152: 243-249.

Silver LM (1995): Mouse Genetics: Concepts and Applications. Oxford University Press, New York.

Smith RS, John SWM, Nashina PM, Sundberg JP (2002): In Sundberg JP (Ed), Systematic Evaluation of the Mouse Eye. Anatomy, Pathology, and Biomethods. CRC, Boca Raton, FL.

Sundberg JP (1994a): The flaky tail ( $f t$ ) mutation, chromosome 3. In Sundberg JP (Ed), Handbook of Mouse Mutations with Skin and Hair Abnormalities Animal Models and Biomedical Tools. CRC, Boca Raton, FL, pp 269-273.

Sundberg JP (Ed) (1994b): Handbook of Mouse Mutations with Skin and Hair Abnormalities. Animal Models and Biomedical Tools. CRC, Boca Raton, FL.

Sundberg JP (1994c): The matted ( $m a$ ) mutation, chromosome 3. In Sundberg JP (Ed), Handbook of Mouse Mutations with Skin and Hair Abnormalities Animal Models and Biomedical Tools. CRC, Boca Raton, FL, pp 345-349.

Sundberg JP, Boggess D (2000): Systematic Characterization of Mouse Mutations. CRC, Boca Raton, FL.

Sundberg JP, Boggess D, Hogan ME, Sundberg BA, Rourk MH, Harris B, Johnson K, Dunstan RW, Davisson MT (1997a): Harlequin ichthyosis. A juvenile lethal mouse mutation with ichthyosiform dermatitis. Am J Pathol 151: 293-310.

Sundberg JP, France M, Boggess D, Sundberg BA, Jenson AB, Beamer WG, Shultz LD (1997b): Development and progression of psoriasiform dermatitis and systemic lesions in the flaky skin $(f s n)$ mouse mutant. Pathobiology 65: 271-286.

Sundberg JP, Montagutelli X, Boggess D (1998): Systematic approach to evaluation of mouse mutations with cutaneous appendage defects. In Chuong M (Ed), Cutaneous Appendages. Molecular Biology Intelligence Unit I, Landes Company, Austin, TX, pp 421-435.

Ward J, Mahler J, Maronpot R, Sundberg JP (2000): Pathology of Genetically Engineered Mice. Iowa State University Press, Ames, IA.

Whittingham DG, Leibo SP, Mazur P (1972): Survival of mouse embryos frozen to -196 degrees and -269 degrees C. Science 178: $411-414$. 